\title{
PENGEMBANGAN MODEL SISTEM DINAMIK PEMENUHAN LOGISTIK BERAS UNTUK MENJAGA STABILITAS HARGA BERAS (STUDI KASUS: PROVINSI JAWA TIMUR)
}

\author{
Joko Suprianto, Erma Suryani \\ Jurusan Sistem Informasi, Fakultas Teknologi Informasi, Institut Teknologi Sepuluh Nopember \\ Kampus Keputih, Sukolilo, Surabaya 60111 \\ Telp: (031) 5999944, Fax: (031) 5964965 \\ E-mail : ${ }^{1}$ joko.super85@gmail.com
}

\begin{abstract}
Rice is still remains a staple food consumption Indonesian society in general, and particularly East Java. Easily cooked, affordable price and available in almost around the country, making it difficult to choose the other basic foodstuffs are comparable to rice. Moreover, the nutritional content of rice is relatively better, when compared with other staples such as cassava, maize and tubers. So it is understandable if the government puts these commodities as a strategic food commodities and even politically. Price stability can be maintained if there is a balance between demand and supply of rice. Logistics Agency (Bulog) Regional Division (DIVRE) East Java is one of the government agencies given the task of keeping the principal national food availability in general and East Java in particular. So here Bulog has a very important role in keeping prices stable by absorbing rice yield and rice from farmers at a price that is not detrimental to the farmers. Researchers focus to examine the relationship between variables that exist in the logistics fulfillment of rice in East Java is the food needs (demand), total rice availability (supply) and the price of rice. The outcome of this research is the creation of a dynamic system model of logistics fulfillment of rice to keep prices stable through several scenarios for demand and supply planning in support of continuity of supply and price stability.
\end{abstract}

\section{Abstrak}

Beras sampai saat ini masih tetap menjadi konsumsi makanan pokok masyarakat Indonesia umumnya, dan Jawa Timur khususnya. Mudah dimasak, harga yang terjangkau dan tersedia di hampir pelosok negeri, menjadikan masyarakat sulit untuk memilih bahan makanan pokok lain yang sebanding dengan beras. Apalagi kandungan gizi beras relatif lebih baik, bila dibandingkan dengan bahan pokok lain seperti ketela pohon, jagung dan umbi-umbian. Sehingga wajar bila pemerintah menempatkan komoditas ini sebagai komoditas pangan strategis dan bahkan politis. Stabilitas harga beras bisa selalu terjaga jika terjadi keseimbangan antara demand dan supply beras. Badan Urusan Logistik (BULOG) Divisi Regional (DIVRE) Jawa Timur merupakan salah satu instansi pemerintah yang diberikan tugas pokok menjaga ketersediaan pangan nasional umumnya dan Jawa Timur pada khususnya. Maka BULOG disini memiliki peran yang sangat penting dalam menjaga stabilitas harga beras dengan menyerap hasil padi maupun beras dari petani dengan harga yang tidak merugikan pihak petani.Peneliti fokus untuk meneliti hubungan antar variabel yang ada dalam pemenuhan logistik beras di Jawa Timur yaitu mengenai kebutuhan pangan (demand), total ketersediaan beras (supply) dan harga beras. Hasil dari penelitian ini adalah terciptanya suatu model sistem dinamik pemenuhan logistik beras untuk menjaga stabilitas harga beras melalui beberapa skenario untuk perencanaan supply dan demand dalam mendukung kontinuitas supply dan stabilitas harga beras..

Kata kunci: beras, sistem dinamik, harga beras.

\section{PENDAHULUAN}

Beras sampai saat ini masih tetap menjadi konsumsi makanan pokok masyarakat Indonesia umumnya, dan Jawa Timur khususnya. Mudah dimasak, harga yang terjangkau dan tersedia di hampir pelosok negeri, menjadikan masyarakat sulit untuk memilih bahan makanan pokok lain yang sebanding dengan beras. Apalagi kandungan gizi beras relatif lebih baik, bila dibandingkan dengan bahan pokok lain seperti ketela pohon, jagung dan umbi-umbian. Sehingga wajar bila pemerintah menempatkan komoditas ini sebagai komoditas pangan strategis, dan bahkan politis. Provinsi Jawa Timur dengan jumlah penduduk mencapai \pm 35 juta jiwa, sebagian besar mengkonsumsi beras sebagai makanan pokok. Data SUSENAS tahun 1999 menunjukkan bahwa konsumsi beras masyarakat Jatim tercatat sebesar 91,52 kg/kapita/tahun. 
Suprianto, dkk., Pengembangan Model Sistem Dinamik Pemenuhan Logistik Beras untuk..

Pada penelitian ini diusulkan untuk melakukan penelitian pengembangan model sistem dinamik pemenuhan logistik beras yang bertujuan untuk menjaga stabilitas harga beras (studi kasus: di Provinsi Jawa Timur). Peneliti fokus untuk meneliti hubungan antar variabel yang ada dalam pemenuhan logistik beras di Jawa Timur yaitu mengenai kebutuhan pangan (demand), total ketersediaan beras (supply) dan harga beras dengan menggunakan kerangka kerja sistem dinamik.

Kerangka kerja Sistem dinamik dapat digunakan untuk menganalisis model dan menghasilkan skenario untuk meningkatkan kinerja sistem karena kemampuan mewakili arus fisik dan informasi, berdasarkan kontrol informasi umpan balik yang terus menerus diubah menjadi keputusan dan tindakan (Suryani, 2009).

\section{METODOLOGI}

Ada teori menyatakan bahwa sistem dinamik merupakan penggambaran dari perilaku sistem yang mana memiliki hubungan interpedensi dan berubah terhadap waktu (Sterman, 2000). Menurut Sterman (2000), bahwa sistem dinamik merupakan cara yang paling populer dalam proses pemodelan karena dapat menggambarkan kondisi lingkungan yang akan dimodelkan semirip mungkin dengan kondisi seperti yang ada dalam lingkungan nyata. Dapat dikatakan bahwa sistem dinamik merupakan umpan balik atau feedback structure yang saling berkaitan dan menuju ke arah keseimbangan.

Dalam buku Sterman (2000) mencoba memberikan gambaran secara umum proses yang terjadi dalam pemodelan sistem dinamik seperti nampak pada gambar 1. Chou (2009), memaparkan dalam jurnalnya bahwa siklus yang ada dalam gambar 1 merupakan bagian dari siklus yang lebih besar dari pembelajaran dan tindakan yang ada pemodelan sistem dinamik yang akan terus berlangsung di organisasi. Sistem dinamik memiliki kemam-puan untuk menggambarkan kemampuan manusia yang bersifat unik sehingga dapat menggambarkan model sesuai dengan dunia nyata. Dalam penerapannya sistem dinamik dapat menerima kompleksitas, nonlinieritas, dan struktur umpan balik yang melekat dalam sistem sosial dan fisik. (Forrester., 1994). Penelitian tentang pengaruh pemodelan sistem dinamis secara umum telah dilakukan oleh beberapa peneliti. Dengan menggunakan kerangka kerja Sistem Dinamik (SD) untuk pemenuhan logistik pangan untuk menjaga stabilitas harga beras di Jawa Timur untuk menggambarkan perilaku stabilitas harga yang ada dan untuk menghasilkan skenario beberapa kebijakan di masa depan untuk meningkatkan pemenuhan logistik pangan serta menjaga stabilitas harga beras.

Ianchovichina (2001), meneliti tentang penggunaan sumber daya dan kemajuan teknologi di bidang pertanian mengenai analisis kesetimbangan dinamis umum. Menurut penelitiannya, beberapa faktor yang mempengaruhi kesetimbangan dinamis umum meliputi Efek pada ekonomi, pertumbuhan penduduk dan sumber daya lingkungan terhadap kebutuhan pangan beras. Gohara (2001), Meneliti sebuah model sistem dinamik untuk estimasi kapasitas produksi pangan dunia di masa mendatang. Menurut penelitiannya, beberapa faktor yang mempengaruhi kapasitas produksi pangan dunia adalah Analisis penawaran dan permintaan makanan di seluruh dunia. Falcon (2004), meneliti menggunakan model iklim untuk meningkatkan Ketahanan Pangan Indonesia. Menurut penelitiannya, beberapa faktor yang mempengaruhi Ketahanan Pangan Indonesia yaitu Hubungan antara perubahan iklim, pasokan dan ketersediaan pangan beras. Kumar (2011), menggunakan simulasi sistem dinamik untuk mendukung keputusan stategis dalam mengembangakan konfigurasi supply beras. Pendekatan sistem dinamik digunakan untuk mempelajari kebiasaan dan hubungan dalam supply untuk produk yang mudah rusak. Dapat disimpulkan bahwa model ini digunakan untuk mengetahui hubungan antar pelaku supply beras dan untuk menganalisis efek dari perubahan nilai dari variabel model. Nurul (2012), meneliti dampak subsidi Pupuk terhadap ketersediaan beras di Malaysia menggunakan pendekatan sistem dinamik. Hasil penelitian ini dapat menyimpulkan bahwa implikasi kebijakan secara keseluruhan menunjukkan produksi beras di Malaysia tidak bisa ditingkatkan tanpa subsidi pupuk dan petani tidak bersedia untuk membeli pupuk sendiri. Hasilnya akan meningkatkan produktivitas pertanian di Malaysia.

\section{HASIL dan PEMBAHASAN}

Pada buku Sterman (2000), pengembangan model sistem dinamik dalam tahap ini perlu dilakukan proses Endogenous Explanation yaitu secara kata "endogen" berarti "timbul dari dalam." Sebuah teori endogen menghasil-kan sistem dinamik melalui interaksi dari variabel yang ada dalam causal loop diagram (CLD) dalam pemenuhan logistik beras di Jawa Timur. Hubungan sebab akibat pemenuhan logistik beras untuk menjaga stabilitas harga beras di jawa Timur pada gambar 1 dapat dijelaskan bahwa faktor yang mempengaruhi kebutuhan pangan adalah populasi penduduk dan 
kebutuhan beras perkapita. Total produksi padi dapat dipenuhi dengan cara meningkatkan produktivitas lahan per hektar dengan menerapkan revitalisasi lahan menggunakan pupuk dan insektisida. Teknologi pengolahan tanah untuk meningkatkan total produksi padi dengan pengolahan tanah yaitu perbaikan saluran dan galengan agar tidak kehilangan air pengairan masuk kedalam petakan sawah. Proses lain dalam pengolahan tanah yaitu pembajakan sawah, menyediakan bibit yang berkualitas, persemaian padi, pengaturan irigasi, pengendalian hama serta penanganan panen dan pasca panen yang tepat. Jumlah produksi padi juga dipengaruhi oleh luas lahan tanam padi dan luas panen padi dapat ditingkatkan dengan cara pembukaan lahan baru maupun alih fungsi lahan. Rasio pemenuhan kebutuhan pangan produksi beras masuk Badan Urusan Logistik (BULOG) Divisi Regional (DIVRE) Jawa Timur dengan menerapkan intensifikasi lahan dan memperluas ekstensifikasi lahan agar produktivitas lahan lama maupun baru tetap produktif.

\subsection{Data}

Data yang digunakan untuk penelitian ini adalah data-data yang didapatkan dari Dinas Pertanian Jatim dan Perum Bulog Jatim yang terdiri dari :

1. Populasi Penduduk Jawa Timur

Data populasi penduduk Jawa Timur dari tahun 2000 - 2011 diperoleh dari Badan Pusat Statistik Provinsi jawa Timur yang sudah diolah.
2. Luas lahan sawah

Data luas lahan sawah tahun 2000 - 2011 diperoleh dari Dinas Pertanian Provinsi Jawa Timur yang sudah diolah.

3. Produktivitas lahan padi per hektar Data produktivitas lahan padi per hektar tahun 2000 - 2011 diperoleh dari Dinas Pertanian Provinsi Jawa Timur yang sudah diolah.

4. Produksi padi

Data produksi padi tahun 2000 - 2011 diperoleh dari Dinas Pertanian Provinsi Jawa Timur yang sudah diolah.

5. Produksi Beras

Data produksi beras tahun 2000 - 2011 diperoleh dari Dinas Pertanian Provinsi Jawa Timur yang sudah diolah.

\subsection{Pemodelan Data}

Pemodelan data dilakukan untuk verifikasi dan validasi hubungan antar variabel (formulasi model) untuk kesesuaian model dengan system nyatanya. Dapat dilihat pada gambar 2 basemodel pemenuhan logistik beras untuk menjaga stabilitas harga.

\subsection{Validasi}

Pengujian terhadap model dari hasil perhitungan mean comparison kurang dari 5\%, sehingga model tersebut dikatakan valid dan benar. Mean Comparison permintaan beras (demand) $3.38 \%$ dan Mean Comparison Supply beras di pasar umum $4.06 \%$.

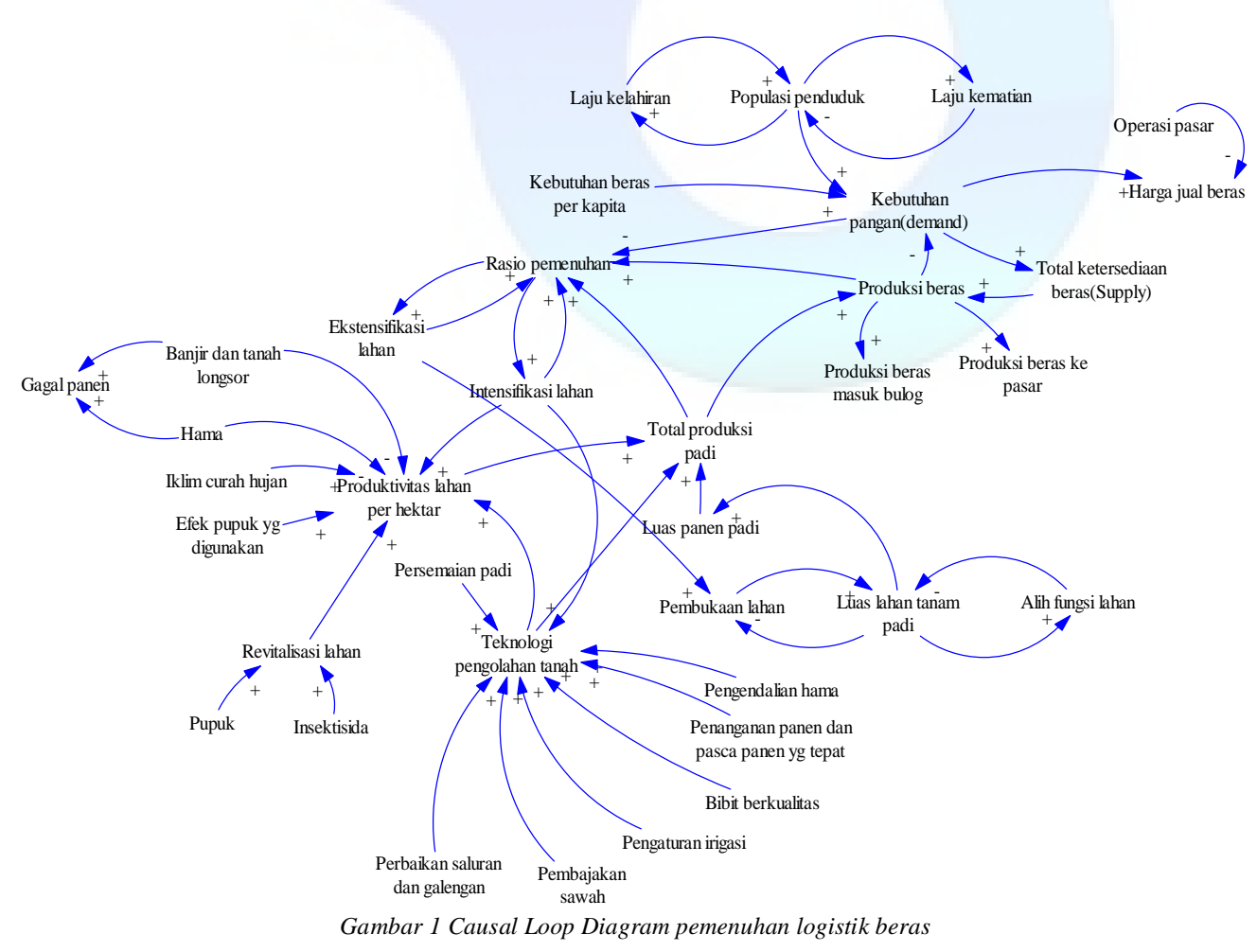




\subsection{Pengembangan skenario kebijakan}

Base Model pemenuhan logistik beras yang peneliti buat valid, langkah selanjutnya membuat rancangan skenario untuk pemenuhan logistik beras. Dalam merancang skenario, dengan cara mengubah nilai parameter yang paling berpengaruh sangat kuat terhadap base model. Untuk mengetahui kinerja sistem dari pemenuhan logistik beras, yang dapat representasikan kemungkinan hasil yang terjadi dimasa mendatang 10 tahun mendatang baik secara optimis (nilai produktivitas tertinggi yang pernah dicapai) maupun pesimis (nilai produktivitas terendah yang pernah dicapai) dan nilai rata-rata produktivitas (most-likely) yang sering terjadi dan struktur berguna untuk pemenuhan logistik beras dengan menambah variabel intensifikasi dengan penggunaan bibit unggul dan memperluas areal tanam melalui ekstensifikasi pola tanam.

\section{a) Skenario Parameter}

\section{$\underline{\text { Skenario Optimistis }}$}

Base model, rata-rata produktivitas beras dari tahun 2000 sampai dengan 2011 saat ini adalah 5,132 ton/hektar berdasarkan data beras menurut Dinas Pertanian Provinsi Jawa Timur. Untuk skenario optimistis ini produktivitas lahan sawah diprediksikan sebesar 8 ton/hektar menurut Dinas Pertanian Provinsi Jawa Timur. Variabel yang nilainya bertambah adalah permintaan beras dan supply beras dipasar umum. Hasilnya dapat dilihat pada gambar 3.

\section{Skenario Pesimistis}

Skenario pesimis ini produktivitas lahan sawah diprediksikan 4,2 ton/hektar berdasarkan data beras menurut Dinas Pertanian Provinsi Jawa Timur. Variabel yang nilainya bertambah adalah permintaan beras dan supply beras dipasar umum. Hasilnya dapat dilihat pada gambar 4.

\section{Skenario Most-likely}

Skenario Most-likely ini produktivitas lahan sawah diprediksikan 5,132 ton/hektar berdasarkan data beras menurut Dinas Pertanian Provinsi Jawa Timur. Variabel yang nilainya bertambah adalah permintaan beras dan supply beras dipasar umum. Hasilnya dapat dilihat pada gambar 5

\section{b) Skenario Struktur}

\section{Skenario Struktur Intensifikasi (Bibit Unggul)}

Skenario intensifikasi adalah berupa pemberian bantuan bibit unggul. Menurut perkiraan Berita Resmi Statistik Provinsi Papua Barat bantuan bibit unggul pada tahun 2013 akan meningkatkan produktivitas sebesar $3,51 \%$, sehingga peneliti memilih menggunakan asumi produktivitas meningkat $3,51 \%$ setiap tahunnya dari tahun 2013-2020. Untuk melakukan scenario struktur ini dengan menambahkan varietas unggul pada base-model dan hasilnya dapat dilihat pada gambar 6 .

\section{Skenario Struktur Ekstensifikasi Lahan}

Skenario struktur ekstensifikasi lahan adalah berupa pembukaan lahan rawa yang belum ditanami. Maksimal pembukaan adalah $75 \%$ sehingga masih ada sisa lahan rawa untuk kebutuhan lain. Hasilnya dapat dilihat pada gambar 7 .

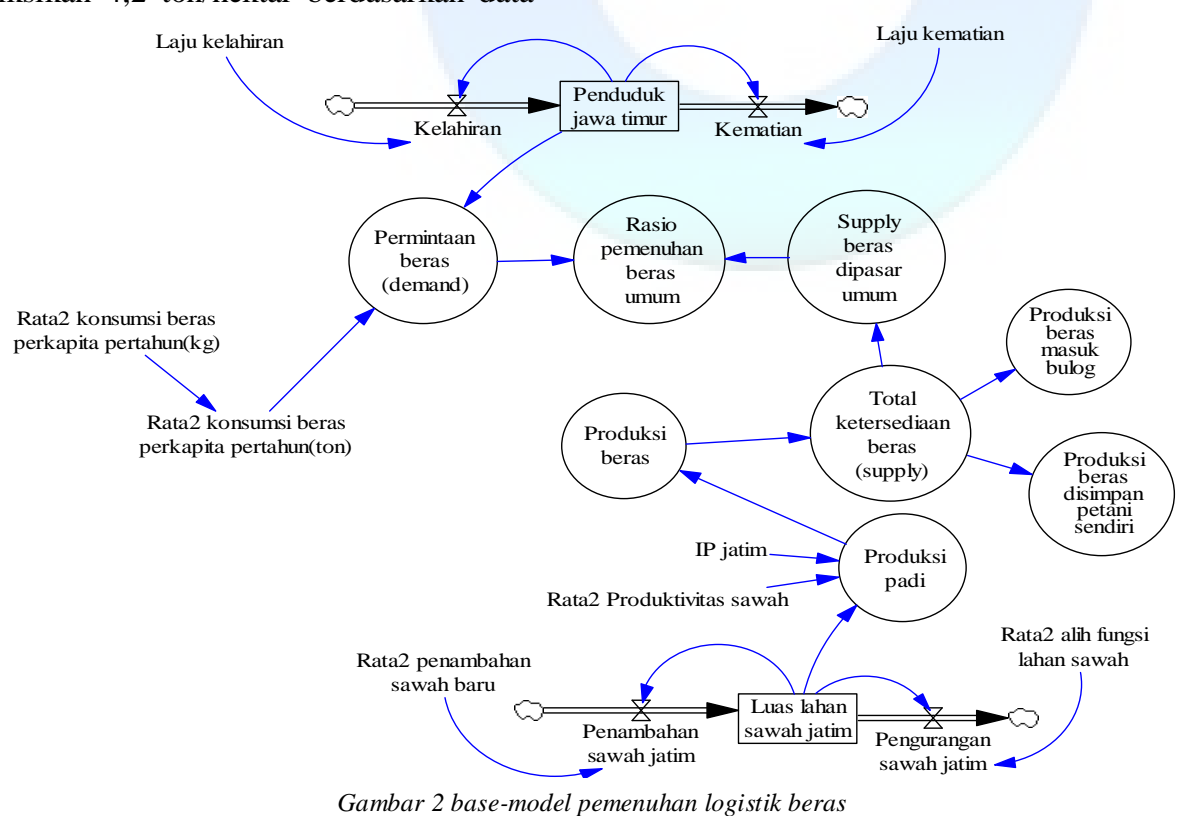


Jurnal Sistem Informasi, Volume 5, Nomor 1, Maret 2014, hlm. 9-14

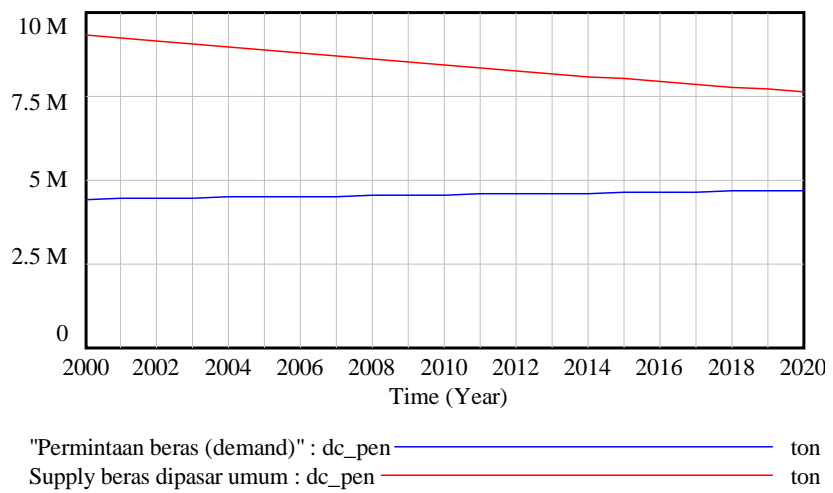

Gambar 3 Grafik perbandingan permintaan beras dan supply beras dipasar umum pada scenario optimistis

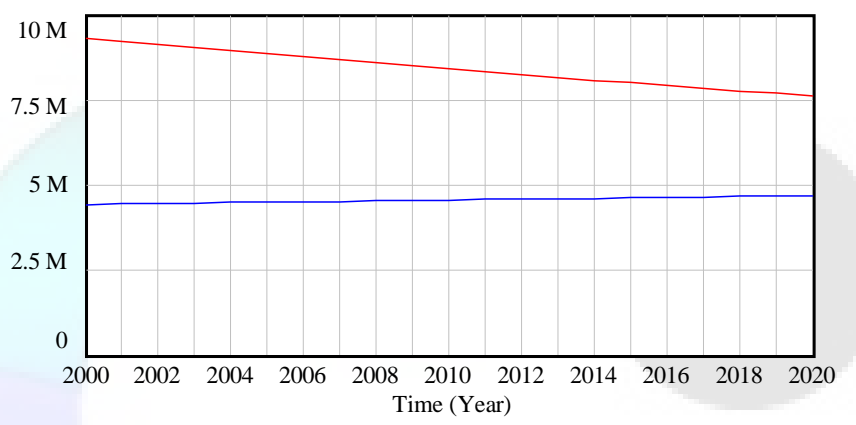

"Permintaan beras (demand)" : dc_pen — ton

Supply beras dipasar umum : dc_pen $\longrightarrow$ ton

Gambar 4 Grafik perbandingan permintaan beras dan supply beras dipaar umum pada scenario pesimistis

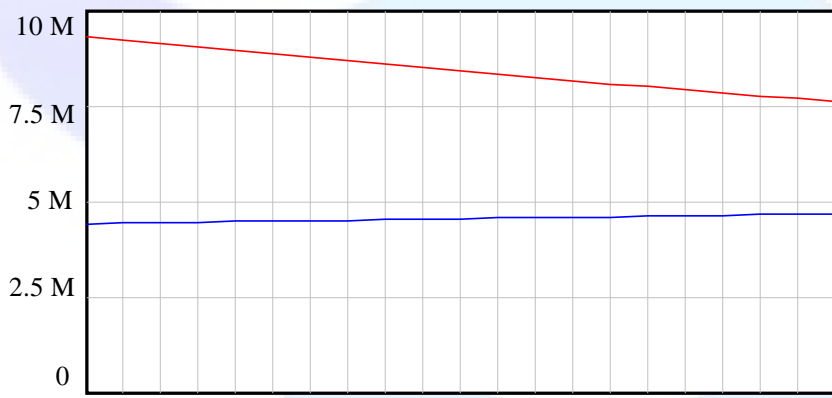

$2000200220042006 \quad 2008 \quad 2010 \quad 2012 \quad 2014 \quad 2016 \quad 2018 \quad 2020$

Time (Year)

"Permintaan beras (demand)" : dc_pen_ ton

Supply beras dipasar umum : dc_pen_ton

Gambar 5 Grafik perbandingan permintaan beras dan supply beras dipaar umum pada scenario Most-likely

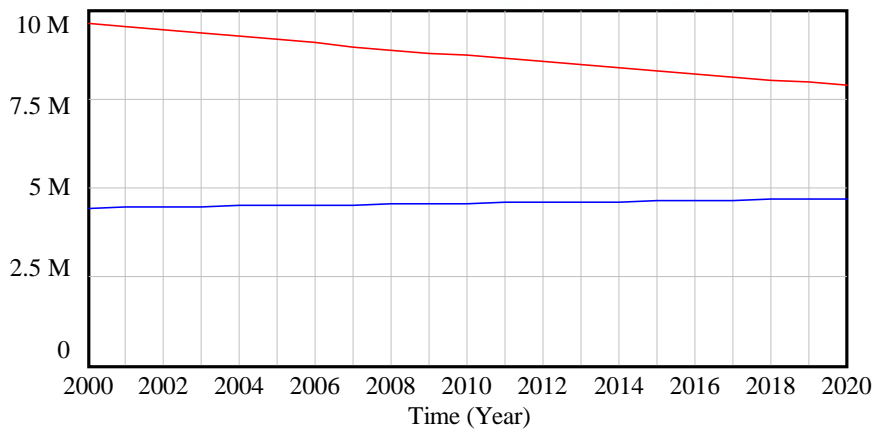

"Permintaan beras (demand)" : dc_pen_ ton

Supply beras dipasar umum : dc pen

ton

Gambar 6 Hasil Skenario Struktur Intensifikasi 


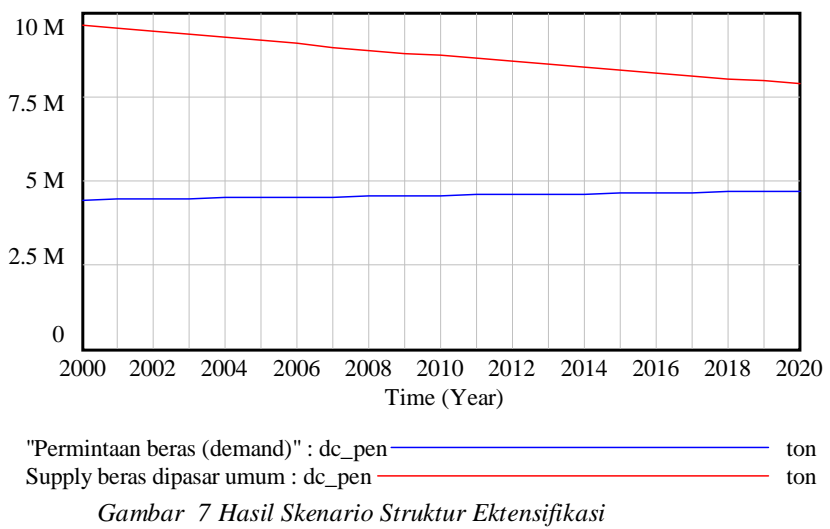

\section{SIMPULAN dan SARAN}

Simpulan dari penelitian ini sebagai berikut:

1. Model yang dikembangkan dalam penelitian ini telah valid melalui pengujian means comparison ditunjukkan dengan nilai $\mathrm{E}<5 \%$ pada permintaan beras (demand) dan supply beras dipasar umum.

2. Total ketersediaan beras tertinggi pada tahun 2000 karena total lahan sawah yang masih luas dibandingkan setelah tahun 2000.

3. Rasio pemenuhan beras Provinsi Jawa Timur dari tahun 2013 - 2020 di atas 1, artinya pemenuhan kebutuhan beras di Provinsi Jawa Timur terpenuhi.

4. Secara umum sampai tahun 2020 provinsi jawa timur mampu memenuhi kebutuhan beras dan tidak perlu impor agar harga beras stabil, sehingga petani merasa untung hasil pertanian diserap bulog dan konsumen sehari-hari tetap aman karena cadangan beras tersedia dan aman.

Pengembangan penelitian selanjutnya dapat ditambahkan lebih banyak variabel yang mempengaruhi produktivitas sehingga dapat dikembangkan skenario intensifikasi dan skenario ekstensifikasi yang lebih beragam.

\section{DAFTAR RUJUKAN}

BPS Provinsi Papua Barat. 2013. Berita resmi statistic No.30/07/91/Th.VII. BPS Propinsi Papua Barat.

Data Statistik Indonesia. 2013. Jumlah dan Laju Pertumbuhan Penduduk. Diambil kembali dari Data Statistik Indonesia: http://www.datastatistik-indonesia.com/portal/index.php. diakses 20 Oktober 2013

Falcon, Walter P. et, al. 2004. Using climate models to improve Indonesian Food Security. Bulletin of Indonesian Economic Studies, Vol. 40, No. 3, 355-77
Forrester, Jay W, 1994. Sistem Dynamics, Sistems Thinking, and Soft OR. Sistem Dynamics Review Summer, Vol. 10, No. 2, page 3 .

Gohara, R. 2001. A System Dynamics Model for Estimation of Future World Food Production Capacity. Unpublished Thesis (M.S.) University of New Hampshire.

Ianchovichina, Elena et, al. 2001. Resource use and technological progress in agriculture: a dynamic general equilibrium analysis. Ecological Economics 38, 275-291.

Kumar, S. and Nigmatullin, A. 2011. "A System Dynamics Analysis of Food Supply Chains - Case Study With Non-Perishable Products ", Simulation Modelling Practice and Theory, Vol. 19, No. 10, pp. 21512168.

Laporan Tahunan Dinas Pertanian Jawa Timur. 2009. Penggunaan Lahan Bukan Sawah (ha) per Kabupaten/Kota. Dinas Pertanian Provinsi Jawa Timur.

Laporan Tahunan Dinas Pertanian Jawa Timur. 2011. Luas mutasi lahan tahun 2011.Dinas Pertanian Provinsi Jawa Timur.

Nurul Nadia Ramli, Mad Nasir Shamsudin, Zainalabidin Mohamed, and Alias Radam. 2012."The Impact of Fertilizer Subsidy on Malaysia Paddy/Rice Industry Using a System Dynamics Approach". International Journal of Social Science and Humanity, Vol. 2, No. 3.

Sterman, J. D. 2000. Business Dynamics: Systems Thinking and Modeling for a Complex World. New York: Irwin/McGrawHill.

Suryani,E., Chou,S.Y., dan Chen, C.H., 2009. Air passenger demand forecasting and passenger terminal capacity expansion: A sistem dynamics framework, Expert Sistems with Applications 37 2324-2339. 